\section{Estudo \\ Ecidebate}

em Testão

Planejamento
Revista Estudo \& Debate, Lajeado, v. 24, n. 3, 2017. ISSN 1983-036X

DOI: http://dx.doi.org/10.22410/issn.1983-036X.v24i3a2017.1323

\title{
A POTENCIALIDADE DOS CONSÓRCIOS INTERMUNICIPAIS FRENTE À POLIITICA NACIONAL DE RESÍDUOS SÓLIDOS: ESTUDO DE CASO NO COREDE - VALE DO TAQUARI, RS, BRASIL
}

\author{
Thanabi Bellenzier Calderan¹, Jane Márcia Mazzarino², Luciana Turati ${ }^{3}$
}

\begin{abstract}
Resumo: A falta de estrutura técnica e financeira acarreta a deficiência na gestáo de resíduos sólidos domésticos e fez com que cerca de três quartos dos municípios do estado do Rio Grande do Sul decidissem terceirizar a gestáo de seus resíduos, elevando os custos dos serviços devido à distância percorrida até a sede da empresa contratada e os valores pagos às empresas para a disposição. Diante da dificuldade em prestar o serviço público à população de forma satisfatória, minimizando os impactos ambientais e apresentando melhorias na gestão dos resíduos, torna-se necessário estudar novas alternativas para o setor. A Lei dos Consórcios Públicos no 11.107/2005 serve como aporte legal e propóe, aos gestores públicos municipais, novos modelos de gestáo compartilhada para o gerenciamento integrado dos resíduos urbanos. O objetivo do artigo é analisar a potencialidade da implantaçáo de consórcios para o gerenciamento de resíduos sólidos urbanos nos municípios que compóem o COREDE - Vale do Taquari, no Estado do Rio Grande do Sul. Sob a abordagem qualitativa, por meio de pesquisa bibliográfica e de campo, com uso de questionários, averiguou-se a possibilidade de consorciamento na regiấo. Os dados construídos por meio da pesquisa evidenciam que há necessidade de uma soluçáo coletiva para a gestão dos resíduos na regiâo, na qual muitos municípios não se adequaram à legislação, e eles têm a seu favor a vantagem de proximidade, portanto há potencialidade de consorciamento, o que depende de questôes subjetivas e partidárias relacionadas aos gestores públicos.
\end{abstract}

Palavras-chave: Resíduos Sólidos Domésticos. Gerenciamento integrado. Consórcio Público Intermunicipal.

\section{TITLE: THE POTENTIALITY OF INTERMUNICIPAL CONSORTIUMS FACE TO THE NATIONAL SOLID WASTE POLICY: CASE STUDY IN COREDE - TAQUARI VALLEY, RS, BRAZIL}

Abstract: State of Rio Grande do Sul to decide to outsource their waste management, raising service costs due to the distance traveled up to the head office of the contracted company and the amounts paid to the

1 Doutoranda em Ambiente e Desenvolvimento pela Univates. Funcionária Pública e professora da Graduação.

2 Doutora em Ciências da Comunicaçấo pela Universidade do Vale do Rio dos Sinos, professora do PPG Ambiente e Desenvolvimento da Univates.

3 Doutora em Direito pela UNISC, professora do PPG Ambiente e Desenvolvimento da Univates. 
companies for a provision. Given the difficulty in providing satisfactory public services to the population, minimizing environmental impacts and presenting improvements in waste management, it is necessary to study new alternatives for the sector. The Public Consortia Law number 11.107/2005 serves as a legal contribution and proposes to municipal public managers new shared management models for the integrated management of urban waste. This article's objective is to analyze the potentiality of the implementation of consortiums for the municipal solid waste management in the municipalities that make up COREDE - Taquari Valley, in the State of Rio Grande do Sul. Under the qualitative approach, through bibliographic and field research with the use of questionnaires, the possibility of consortium in the region was investigated. The data built by the research shows that there is a need for a collective solution for waste management in the region, in which many municipalities have not complied with the legislation, and they have the advantage of proximity, therefore there is potential for consortium, depending on subjective and partisan issues related to public managers.

Keywords: Domestic Solid Waste. Integrated management. Intermunicipal Public Consortium.

\section{INTRODUÇÁO}

A Constituição Federal de 1988 (BRASIL, 1988), descentraliza responsabilidades dos Estados e da União fazendo com que os municípios assumam a gestão de projetos nas áreas de infraestrutura, saúde, educação, segurança, proteção e preservação ambiental, o que inclui a gestão de resíduos sólidos domésticos, dentre outros (artigo 29, 30, 196 a 198).

A Política Nacional de Resíduos Sólidos (Lei no 12.305/2010) impóe como metas a eliminação e recuperação de lixões, associadas à inclusão social e à emancipação econômica de catadores de materiais reutilizáveis e recicláveis, seguindo a ordem de prioridade de não geração, redução, reutilização, reciclagem, tratamento e disposição final ambientalmente adequada dos rejeitos (BRASIL, 2010). O caminho é a construção de aterros sanitários.

De acordo com Silva (2011), os aterros sanitários configuram a maneira correta e segura de disposição final de resíduos, exigindo para sua eficiência e eficácia que o processo de escolha da sua área seja feito atentando para todos os aspectos que interferem, tais como: a avaliação de critérios ambientais (geologia, geotecnia, recursos hídricos etc.), de uso e ocupação do solo (legislaçóes, titularidade da área, núcleos populacionais, etc.) e operacionais (infraestrutura, clinografia, espessura do solo, etc.). O processo de seleção de áreas livres que atendam às exigências legais e técnicas para a construçâo de aterros sanitários é minucioso, dificultando o processo.

Isso quando observa-se, na sociedade contemporânea, que prolifera-se a produção de resíduos, devido ao aumento da demanda de consumo, especialmente dos produtos processados e industrializados, aliado a um contexto social em que os indivíduos ignoram suas responsabilidades para com o meio ambiente. Esta situação gera um problema que se complexifica, quando os municípios deparam-se com cada vez menos áreas para a disposição dos resíduos, o que dificulta o cumprimento das suas atribuiçóes legais.

Quando os municípios têm este tipo de dificuldade para a prestação dos serviços públicos de qualidade e eficiente aos cidadãos, pode desencadear a responsabilizaçáo dos gestores municipais. Uma das soluçôes usadas pelos municípios é a terceirização de seus serviços. $\mathrm{Na}$ Regiáo Sul, os investimentos voltados ao mercado de limpeza urbana atingiram o montante de 3.170 milhôes no ano de 2016. Deste valor 73,60\% foi investido na iniciativa privada, terceirizando serviços e apenas $26,40 \%$ do valor foi destinado ao setor público (ABRELPE, 2016, p. 35). A terceirização corresponde a um aumento considerável 
nos gastos públicos, em especial, para os municípios que se localizam distantes da sede da empresa contratada (CALDERAN, 2013).

Outra possibilidade é a solução coletiva a partir do consorciamento. Os consórcios públicos constituem uma possibilidade de soluçáo para os gestores municipais porque facilitam a execução de obras e serviços essenciais, com a união de esforços. Segundo informaçóes disponibilizadas pelo Observatório dos Consórcios Públicos e do Federalismo (OCPF), atualmente, o Brasil possui 695 Consórcios Públicos. Destes apenas 101 atuam na área de resíduos sólidos (OCPF, 2016). O Estado do Rio Grande do Sul possui 48 consórcios públicos (OCPF, 2016), porém apenas 6 atuam diretamente na gestão de resíduos. Os demais voltam-se principalmente para as áreas de turismo, saúde, desenvolvimento, planejamento e gestão.

O objetivo deste estudo é analisar a potencialidade da implantação de consórcios para o gerenciamento de resíduos sólidos urbanos nos municípios que compóem o COREDE Vale do Taquari, no Estado do Rio Grande do Sul. A abordagem metodológica é qualitativa, realizada por meio de pesquisa bibliográfica e de campo, com uso de questionários.

Este estudo é absolutamente relevante, já que a produção crescente de resíduos sólidos domésticos por cada cidadão impõe a necessidade de solução para este problema ambiental e social, o que pode passar pela gestão compartilhada entre municípios em situação de vizinhança geográfica, para sua adequação à legislação. No caso do Vale do Taquari, onde a proximidade é grande, mostra-se pertinente avaliar a potencialidade deste tipo de solução, defendida por diversos autores.

\section{REFERENCIAL TEÓRICO}

\subsection{Cenário de gestáo dos resíduos sólidos urbanos}

\subsubsection{Brasil}

Em 2014, a geração de resíduos foi de aproximadamente 78,6 milhóes de toneladas, índice superior à taxa de crescimento populacional no País no período, que foi de $0,9 \%$. Houve um aumento de 3,20\% no total de RSU coletados em 2014 em relação a 2013 (ABRELPE, 2014).

Já entre 2015 e 2016, os números referentes à geração de RSU revelam um total anual de quase 78,3 milhóes de toneladas no país, resultante de uma queda de $2 \%$ no montante gerado em relaçáo à 2015. A coleta em 2016 foi de 71,3 milhóes de toneladas, o que registrou um índice de cobertura de $91 \%$ para o país, pequeno avanço comparado ao ano anterior, evidenciando que 7 milhóes de toneladas de resíduos tiveram destino impróprio (ABRELPE, 2016). 
Quanto à destinação final dos RSU, no Brasil, em 2014, manteve-se estável em relação ao ano anterior: $58,4 \%$ de destinação final adequada, portanto, para aterros sanitários (ABRELPE, 2014). Em relação a 2015 e 2016 a disposição final dos RSU coletados demonstrou queda de $0,3 \%$ comparado ao índice do ano anterior, de 58,7\% ou 41,7 milhóes de toneladas enviadas para aterros sanitários. O caminho da disposição inadequada continuou sendo trilhado por 3.331 municípios brasileiros, que enviaram mais de 29,7 milhóes de toneladas de resíduos, correspondentes a 41,6\% do coletado em 2016, para lixóes ou aterros controlados, que não possuem o conjunto de sistemas e medidas necessários para proteção do meio ambiente contra danos e degradaçóes (ABRELPE, 2016).

Mesmo com uma legislação mais restritiva e apesar dos esforços empreendidos em todas as esferas governamentais, a destinação inadequada de RSU se faz presente em todas as regiōes e estados brasileiros (ABRELPE, 2016, p. 19). Dos 5.570 municípios do Brasil, 3.331 destinaram seus resíduos inadequadamente em 2016 (tabela 01).

Tabela 01 - Quantidade de Municípios por tipo de destinação adotada em 2016

\begin{tabular}{c|c|c|c|c|c|c}
\hline \multirow{2}{*}{ Destinação final } & \multicolumn{7}{|c}{2016 - Regiōes e Brasil } \\
\cline { 2 - 7 } & Norte & Nordeste & Centro-oeste & Sudeste & Sul & Brasil \\
\hline Aterro Sanitário & 92 & 458 & 161 & 822 & 706 & 2.239 \\
\hline Aterro Controlado & 112 & 500 & 148 & 644 & 368 & 1.772 \\
\hline Lixão & 2456 & 836 & 158 & 202 & 117 & 1.559 \\
\hline & $\mathbf{4 5 0}$ & $\mathbf{1 . 7 9 4}$ & $\mathbf{4 6 7}$ & $\mathbf{1 . 6 6 8}$ & $\mathbf{1 . 1 9 1}$ & $\mathbf{5 . 5 7 0}$ \\
\hline
\end{tabular}

Fonte: ABRELPE, Panorama dos resíduos sólidos no Brasil, (2016, p. 19).

Os lixóes foram usados nas cinco regióes do Brasil. No total 2.239 (40,19\%) municípios do país adotaram o aterro sanitário como forma de disposição de seus resíduos, $1.772(31,81 \%)$ adotaram o aterro controlado e 1.559 (27,98\%) municípios ainda enviam seus resíduos para lixóes. A coleta seletiva de resíduos sólidos no ano de 2016 atinge 3.878 municípios do país $(69,62 \%)$, havendo um crescimento em relação a 2015 (3.859) (ABRELPE, 2016, p. 17).

Os dados apontam que o Brasil precisa avançar rapidamente em busca de uma solução para o destino final dos resíduos sólidos domésticos, pois constata-se que o volume de resíduos gerados aumenta rapidamente, enquanto que os investimentos no setor têm sido limitados, dificultando a criação de soluçóes adequadas à legislação.

\subsubsection{Rio Grande do Sul}

De acordo com o Plano Estadual de Resíduos Sólidos Rio Grande do Sul (PERS) de 2014, o estado do Rio Grande do Sul possui 497 municípios, com população estimada de 10.984.054 habitantes, sendo que desses 9.382 .950 residem na zona urbana, enquanto 
que 1.601.104 residem na área rural. Sendo que 91,54\% dos municípios do estado são de pequeno porte, conforme dados apresentados na Tabela 02.

Tabela 02- Taxas de geração de resíduos per capita consideradas para o estado do RS

\begin{tabular}{l|c|l|c}
\hline Porte do município & No de município & \multicolumn{1}{|c}{$\begin{array}{c}\text { Faixa populacional } \\
\text { (habitantes) }\end{array}$} & $\begin{array}{c}\text { Geraçáo per capita } \\
\text { (kg/hab.dia) }\end{array}$ \\
\hline Pequeno porte & 455 & Até 50.000 & 0,65 \\
\hline Médio Porte & 38 & De 50.001 a 300.000 & 0,8 \\
\hline Grande porte I & 3 & De 300.001 a 1 milhão & 0,9 \\
\hline Grande porte II & 1 & Mais de 1 milhão & 1,1 \\
\hline
\end{tabular}

Fonte: RIO GRANDE DO SUL. PERS, (2014).

De acordo com a tabela 02, a estimativa de geração de RSU no Estado varia de 0,65 a $1,1 \mathrm{~kg}$ por habitante diariamente, aumentando conforme cresce o porte do município. Mesmo assim, apenas $45 \%$ dos municípios possuem iniciativa de coleta seletiva (PERS- RS, 2014).

Segundo estudo realizado pela Fundação Estadual de Proteção Ambiental (FEPAM) de agosto de 2014, o Estado do Rio Grande do Sul possuía 60 unidades de disposição de RSU em operação. Dessas, 41 foram consideradas inadequadas e 19 adequadas à legislação (PERS- RS, 2014). Das 60 unidades, 48 delas são geridas por consórcios e por municípios e 12 unidades são privadas.

A Lei no 11.107/2005 possibilita a constituição de Consórcio Público como órgão autárquico integrante da administração pública de cada município associado, contratado entre os entes federados consorciados. A lei institui o Contrato de Consórcio celebrado entre os entes consorciados que contém todas as regras da associação; o Contrato de Rateio para transferência de recursos dos consorciados ao Consórcio, e o Contrato de Programa que regula a delegação da prestação de serviços públicos, de um ente da Federação para outro ou, entre entes públicos e o Consórcio Público (BRASIL, 2011, p. 19).

Sabe-se que, atualmente, 132 municípios do estado do Rio Grande do Sul enviam seus resíduos para o município de Minas do Leão na Empresa SIL - Soluçóes Ambientais Ltda, (26\%) (PERS- RS, 2014).

No Estado do Rio Grande do Sul, dispondo seus resíduos de forma não autorizada pela legislação, ou seja, 19\% dos municípios dispóem seus resíduos de forma irregular (lixóes ou aterros controlados) (PERS- RS, 2014), p. 242). Destes, grande parte são municípios de pequeno porte. No Brasil, municípios com menos de 20.000 hab (pequeno porte) dependem em grande parte de sua receita dos recursos vindos do Fundo de Participação dos Municípios (FPM) (SOARES, 2011, texto digital). Embora os municípios de pequeno porte estejam amparados pelos recursos vindos da FPM, em muitos casos, ainda não é suficiente para suportar o ônus da implantação e gerenciamento de um aterro sanitário. Essa problemática, ainda está associada à falta de iniciativas para solucionar questão de saneamento básico. 


\subsection{O consorciamento para a gestáo dos resíduos sólidos urbanos}

A Constituição da República Federativa do Brasil, estabelece nos artigos 145 a 162 as competências tributárias dos entes da Federação, ao mesmo passo que nos artigos 21 a 32 prevê os respectivos encargos ou serviços públicos pelos quais são responsáveis (BRASIL, 1988).

O aumento significativo das despesas na esfera municipal à gestão insuficiente e a burocracia implícita nos processos públicos faz com que os recursos financeiros não acompanhem o acréscimo das atribuições. Assim, fez-se necessário buscar novas soluçóes para cumprir de modo eficiente as políticas públicas desenhadas pela Constituição e pela PNRS. Nesse contexto os consórcios surgem como um importante instrumento de cooperação técnica e financeira entre os Municípios e os Governos do Estado, do Distrito Federal e da União, sempre tendo em vista o atendimento de políticas públicas voltadas para melhoria da qualidade de vida, o que inclui a gestáo dos resíduos domésticos.

Num rápido e lógico raciocínio é fácil prever que tudo o que é ou foi fabricado ou construído um dia será descartado, tornando-se resíduo e, portanto, necessitando ter um fim ambientalmente sustentável. A gestão e gerenciamento inadequados dos resíduos sólidos domésticos causam impactos socioambientais, tais como a degradação do solo, comprometimento dos corpos d'água, as enchentes, a poluição do ar e a proliferação de vetores tornando os centros urbanos locais insalubres (BESEN, 2011).

A PNRS (Lei $\mathrm{n}^{\circ}$ 13.205/2010) veio estabelecer princípios, objetivos e instrumentos, bem como diretrizes e normas para o gerenciamento dos resíduos no país. Incentiva claramente a formação de associações intermunicipais que permitam a estabilização da gestão dos resíduos, com os municípios compartilhando as tarefas de planejar, regular, fiscalizar e prestar serviços de acordo com tecnologias adequadas à sua realidade regional (BRASIL, 2010).

A mesma lei prioriza o acesso aos recursos da União e aos incentivos ou financiamentos destinados a empreendimentos e serviços relacionados à gestão de resíduos sólidos ou à limpeza urbana e manejo de resíduos sólidos aos Consórcios Públicos, constituídos na forma da Lei no 11.107, de 2005, para realização de objetivos de interesse comum.

Desde 2014, todas as prefeituras deveriam ter construído aterros sanitários adequados ambientalmente, onde só poderiam ser depositados os resíduos (rejeitos) sem qualquer possibilidade de reaproveitamento ou compostagem. Contudo, dos cerca de 5570 municípios brasileiros, mais de metade deles (3.914) possui até 20 mil habitantes, ou seja, são municípios de pequeno ou médio porte (IBGE, 2010), o que pelo fato de terem pouca estrutura e condições técnicas e financeiras, dificulta o cumprimento adequado e eficiente da legislação ${ }^{4}$.

4 [...] articular açóes normativas, operacionais, financeiras e de planejamento que uma administração municipal desenvolve, apoiada em critérios sanitários, ambientais e econômicos, para coletar, tratar e dispor o lixo de uma cidade, ou seja: é acompanhar de forma criteriosa todo o ciclo dos resíduos, da geração à disposição final ("do berço ao túmulo"), empregando as técnicas e tecnologias mais compatíveis com a realidade local (LIMA, 2003, p. 53). 
Com o consorciamento é possível a implantação de aterros, com usinas de triagem, coleta seletiva, tratamentos dos resíduos, o que seria impossível técnica e financeiramente para um município sozinho gerenciar 5 .

O elevado custo de implantação e operação dos aterros sanitários torna-os inviáveis para muitos municípios, fazendo com que alguns destinem seus RSU para aterros sanitários particulares, denominados Centrais de Recebimento de RSU. Outra solução é o estabelecimento de aterros de RSU intermunicipais, muitas vezes administrados através de consórcios entre os municípios, isto porque a legislação ambiental está cada vez mais rígida e requer grandes investimentos por parte dos municípios na coleta, destinação e tratamento dos resíduos sólidos, principalmente quanto aos resíduos urbanos.

De acordo com Sinoel Batista et al. (2011b, p. 42) além da necessidade de grandes investimentos e de açóes de médio e longo prazo, são necessárias açôes de planejamento de maior intensidade e alcance, o que implica em uma melhor estruturação de gestão. Nesta seara, os consórcios públicos surgem como uma solução, dando uma nova visão para a gestão pública servindo como instrumentos para auxiliar no planejamento regional e na solução de problemas comuns vivenciados entre os entes federados.

A Lei dos Consórcios é o aporte legal para gestão compartilhada de resíduos sólidos incentivada pela PNRS em seu artigo 18:

[...] serão priorizados no acesso aos recursos da União os Municípios que: optarem por soluçôes consorciadas intermunicipais para a gestâo dos resíduos sólidos, incluída a elaboração e implementação de plano intermunicipal, ou que se inserirem de forma voluntária nos planos microrregionais de resíduos sólidos referidos (BRASIL, 2010).

Também no seu Artigo 19 a Lei se refere às soluçōes consorciadas, uma vez que exige que, os planos municipais de gestão de resíduos, estes deverão conter: identificação das possibilidades de implantação de soluções consorciadas ou compartilhadas com outros Municípios, considerando, nos critérios de economia de escala, a proximidade dos locais estabelecidos e as formas de prevenção dos riscos ambientais (BRASIL, 2010).

No tocante aos incentivos financeiros, o Art. 45 da Lei reitera que os consórcios públicos constituídos nos termos da Lei 11.107, de 2005, com o objetivo de viabilizar a descentralização e a prestação de serviços públicos que envolvam resíduos sólidos têm prioridade na obtenção dos incentivos instituídos pelo Governo Federal (BRASIL, 2010).

5 [...] minimizando os impactos ambientais, e consiste em um método que utiliza princípios de engenharia para confinar os resíduos sólidos à menor área possível e reduzi-los ao menor volume permissível, cobrindoos com uma camada de terra na conclusáo de cada jornada de trabalho, ou a intervalos menores, se for necessário (ABNT, 1984). Outra forma de disposição final é o aterro controlado onde os RSU são dispostos no solo sem a utilização de métodos de controle que minimizem os impactos ambientais (ABNT, 1985). Atualmente a Fundação Estadual de Proteção Ambiental (FEPAM) não licencia a operaçáo de aterros controlados, pois essa técnica não garante um controle ambiental seguro, considerando que estes não dispóem de impermeabilização de base, sistema de tratamento de lixiviado ou de drenagem dos gases gerados (GOMES, 2010, p. 25). 
A Lei no $11.445 / 07$ que estabelece as diretrizes nacionais para o saneamento básico e para a política federal de saneamento básico e também faz referência aos consórcios públicos. A lei incentiva açóes de saneamento consorciada em seus artigos 14, 15, 48 e 49, quando estimula que haja: um único prestador do serviço para vários Municípios contíguos ou não; na prestação regionalizada propóe convênios de cooperação entre entes da federação ou por consórcio público de direito público integrado pelos titulares dos serviços; estímulo à implementação de infraestruturas e serviços comuns a Municípios, mediante mecanismos de cooperação entre entes federados.

Portanto, de acordo com os dispositivos legais, o consórcio público é considerado o mecanismo mais adequado para realizar a prestação regionalizada dos serviços públicos de saneamento básico ou no âmbito da gestão associada, para exercer as funçóes de regulação e fiscalização da prestação regionalizada, inclusive para a delegação conjunta da prestação dos serviços de titularidade dos municípios consorciados (PEIXOTO, 2008, p. 40).

A gestão de resíduos sólidos urbanos através de consórcios públicos traz uma série de benefícios sociais e ambientais, dentre os quais pode-se citar: a) economia no processo de captação e tratamento de água para abastecimento das cidades, pois o recurso não estará contaminado pelo chorume emanado dos lixōes; b) economia de recursos naturais, através da reciclagem dos materiais triados; c) melhoria da qualidade de vida dos catadores que trabalham nos lixōes, porque com a criação de um consórcio estes indivíduos poderão se organizar em cooperativas, trabalhando em locais salubres e com equipamentos adequados; entre outros (MORAES, 2012, p. 1.176).

As experiências de consórcios existentes buscam resgatar os conceitos de cooperaçáo intergovernamental e solidariedade e podem auxiliar a potencializar ações de articulação microrregional. Os consórcios têm sido apontados como um instrumento que permite ganhos de escala nas políticas públicas, além de ser um novo modelo gerencial que pode viabilizar a gestão microrregional. Esses têm possibilitado a discussão de um planejamento regional, a ampliação da oferta de serviços por parte dos municípios, a racionalização de equipamentos, a ampliação de cooperaçáo regional, a flexibilização dos mecanismos de aquisição de equipamentos e de contratação de pessoal, entre outras.

O consórcio público justifica-se em função de necessidades comuns entre entes da federação. Há sempre uma motivação concreta em que a cooperação seja necessária para melhor resolver determinadas demandas. Isoladamente um ente federado, seja ele Município, Estado, Distrito Federal ou mesmo a União, podem ter dificuldades de assegurar a melhor solução para problemas complexos cuja solução envolve múltiplos esforços, comprometimento de vários atores e articulação permanente entre eles. A Lei ${ }^{\circ}$. 11.107, de 6 de abril de 2005 dos consórcios públicos garante a segurança jurídica necessária para açóes cooperadas como um elemento estratégico na promoção do desenvolvimento regional.

Neste sentido, realizou-se o estudo empírico no Vale do Taquari, na região central do Rio Grande do Sul, com a finalidade de averiguar as potencialidades e disposição dos municípios para a formação de consórcios para a gestão de resíduos sólidos domésticos. 


\section{METODOLOGIA}

A pesquisa é qualitativa, do tipo exploratória e descritiva. Quanto aos meios baseiase na pesquisa bibliográfica e de campo envolvendo os municípios do COREDE-Vale do Taquari, regiáo oficialmente determinada pelo Governo do Estado do RS composta por 36 municípios.

A pesquisa de campo foi realizada com a aplicação de questionários junto aos responsáveis por informações sobre resíduos em cada município, especialmente tendo sido indicados por estes funcionários dos setores de saneamento básico e/ou meio ambiente.

O questionário foi composto por três blocos contendo questóes abertas, fechadas e mistas. O Bloco A intitulado: "Gestão municipal dos resíduos sólidos domésticos” foi organizado em 11 questóes que visam compreender diferentes aspectos sobre a gestão de resíduos do município. No B 3 questóes objetivaram identificar as informaçóes do servidor acerca da PNRS (metas, objetivos e mecanismos) bem como a adequaçáo do município às exigências da PNRS. E com o BLOCO C buscou-se averiguar, por meio de quatro questôes, informaçóes do servidor acerca dos consórcios públicos e analisar a disposição para a formação de consórcios intermunicipais na região. Os dados foram coletados ao longo de 2015 e representam 100\% dos municípios incluídos na amostra.

\subsection{Caracterizaçáo da área de estudo}

Os COREDEs foram criados em 1994 objetivando a promoção e o desenvolvimento regional numa dada regiâo. Atualmente existem 26 COREDEs no Estado do Rio Grande do Sul (POSTAL; CONTO, 2010). A presente pesquisa restringe-se ao COREDE Vale do Taquari, denominado como Conselho de Desenvolvimento do Vale do Taquari (CODEVAT).

O CODEVAT é composto por 36 municípios (Anta Gorda, Arroio do Meio, Arvorezinha, Bom Retiro do Sul, Canudos do Vale, Capitão, Colinas, Coqueiro Baixo, Cruzeiro do Sul, Dois Lajeados, Doutor Ricardo, Encantado, Estrela, Fazenda Vilanova, Forquetinha, Ilópolis, Imigrante, Lajeado, Marques de Souza, Muçum, Nova Bréscia, Paverama, Poço das Antas, Pouso Novo, Progresso, Putinga, Relvado, Roca Sales, Santa Clara do Sul, Sério, Tabaí, Taquari, Teutônia, Travesseiro, Vespasiano Corrêa e Westfália).

O Produto Interno Bruto (PIB) da região superou $\mathrm{R}$ \$ 9,5 Bilhôes (3,29\% do PIB estadual). A indústria respondia por $27,54 \%$ desse total; o setor de serviços, por $27,54 \%$, e a agropecuária, por 16,04\%. No PIB per capita o Vale chegou a R\$28.669,24 em 2012. Possui uma diversidade característica de regióes que baseiam sua economia em pequenas e médias propriedades. Suas divisas de solo e geografia fazem com que prevaleçam minifúndios de propriedade familiar. É reconhecidamente produtora de alimentos e praticamente $80 \%$ da sua atividade produtiva gira em torno do agronegócio (UNIVATES, 2012).

A localização geográfica - dista $117 \mathrm{~km}$ de Porto Alegre e $110 \mathrm{~km}$ da região de Caxias do Sul - e a malha rodo-hidro-ferroviária colocam o Vale do Taquari numa posição estratégica favorável ao desenvolvimento socioeconômico. 
O aparecimento de indústrias e o desenvolvimento do comércio e do setor de serviços provocaram mudanças significativas nos últimos 30 anos. Em 1970, 74,27\%\% da população vivia no meio rural e, passadas três décadas, o quadro praticamente se inverteu: hoje 73,84\% vive na zona urbana. Nos pequenos municípios se destaca o setor da agropecuária, enquanto nos municípios maiores sobressaem-se atividades ligadas à indústria e ao setor de serviços e comércio.

A maior parte dos habitantes do Vale do Taquari é descendente de imigrantes italianos, alemães e açorianos. Anterior à chegada dos imigrantes europeus à região, cabe registro à presença de indígenas de diversas origens - em sua maior parte, guaranis. Atualmente são 352.943 habitantes (FEE, 2015). Considera-se que cada pessoa no estado do Rio Grande do Sul, produz em média $1 \mathrm{~kg}$ de resíduo por dia (PERS, 2014), somando-se cerca de 300 toneladas de produção de resíduos gerados no Vale do Taquari. Essa constatação, leva-nos a questionar: Qual o tratamento dado pelo setor público aos resíduos produzidos no Vale ao Taquari, integrado ao CODEVAT?

\section{RESULTADOS}

De acordo com Zanella (2011) a partir de 2004, surgem dois Consórcios Intermunicipais de Desenvolvimento no Vale do Taquari, CG8 e o CG10, propondo o reagrupamento dos pequenos municípios, como forma de fazerem frente às inúmeras demandas impostas pela realidade atual e aos limites impostos pela extrema fragmentação, não somente a territorial, mas também dos interesses políticos, econômicos e sociais, que passam a colocar em risco as promessas que haviam garantido o apoio da maioria à emancipação das novas municipalidades.

Com o passar do tempo visualiza-se a necessidade dos municípios, principalmente os de pequeno porte, buscarem um redesenho da base territorial. $\mathrm{O}$ autor lembra que o associativismo já é comum na região do Vale do Taquari. Os municípios estão cada vez mais articulados, tendo criado órgãos como a Associação dos Municípios do Vale do Taquari (AMVAT), que reúne todos os municípios do Vale e a Associação dos Municípios de Turismo da Região dos Vales (AMTURVALES), que também reúne os municípios, com o objetivo de fomentar o turismo na região. Baseado nestas açóes que deram certo, alguns municípios decidiram aproximar-se ainda mais, formando o Consórcio Público Intermunicipal para Assuntos Estratégicos CIPAE-G8.

É no contexto de uma dinâmica regional intensa que, oito Municípios do Vale do Rio Pardo (Forquetinha, Santa Clara do Sul, Progresso, Canudos do Vale, Boqueirão do Leão, Sério, Cruzeiro do Sul e Marques de Souza), todos ex-distritos de Lajeado, celebraram entre si, um Protocolo de Intençóes formalizando a implantação de Consórcio Intermunicipal de Desenvolvimento Integrado e Sustentável, entre os Municípios componentes do G8.

No mesmo contexto instala-se também o Consórcio Intermunicipal de Desenvolvimento Integrado e Sustentável - CG10, integrado pelos municípios de Encantado, Doutor Ricardo, Nova Bréscia, Coqueiro Baixo, Putinga, Ilópolis, Arvorezinha, Itapuca, Anta Gorda e Relvado, cuja data de fundação foi em 18/03/2011. 
Os consórcios G8 e o G10, formam-se a partir de um quadro de fragmentação dos municípios emancipados de Lajeado e Encantado, com pouca representaçáo política e econômica no COREDE - Vale do Taquari e da AMVAT. O G10 é um exemplo de consórcio que apesar do esforço desprendido pelas municipalidades para sua formação política e legal, na prática não se efetivou, restando apenas o G8 em pelo funcionamento na regiáo.

O estudo empírico indica apenas 56\% dos municípios que compóem o G8 implantaram a coleta seletiva, quando o artigo 18 da Lei 12.305/2010 prioriza o acesso a recursos federais aos municípios que implantaram a coleta seletiva.

Mesmo após o advento da lei 44\% dos municípios do CODEVAT não implantaram a coleta seletiva. Número expressivo por já haver passado 5 anos da aprovação da Lei sem que suas metas tenham sido atingidas. Este cenário extrapola a região do estudo já que apenas $62 \%$ dos municípios brasileiros já haviam registrado alguma iniciativa de coleta seletiva, conforme os dados da ABRELPE (2013) até entáo. Em paralelo, identificam-se outras iniciativas como a disponibilizaçáo de pontos de entrega voluntária ou convênios com cooperativas de catadores que, contudo, não abrangem a totalidade do território ou da população do município.

Averiguou-se a existência de cooperativa de catadores, o que está previsto na PNRS. É a partir do trabalho dos catadores que os aterros sanitários das cidades têm uma vida útil maior, que as prefeituras municipais economizam recurso no serviço de coleta de lixo convencional e que os catadores almejam alguma dignidade. Constatou-se que apenas $6 \%$ dos municípios possuem cooperativa de catadores o que corresponde a apenas 2 municípios (Lajeado e Taquari) que conseguem gerar economia e renda a esses trabalhadores.

O município que lidera o ranking de geração de resíduos é o munícipio de Lajeado, por ser o de maior porte dos municípios respondentes. O volume coletado pelo município é de 1.870 toneladas/mês (coleta seletiva representa 70 toneladas/mês e o resíduo orgânico 60 toneladas dia).

Em segundo lugar segue o município de Progresso com 840 toneladas/mês, em terceiro lugar o município de Estrela com 520 toneladas/mês. Na somatória dos resíduos dos municípios que informaram o volume mês (32) obteve-se o resultado de 3.523,85 toneladas/mês.

Verificou-se que os municípios respondentes que mais dispensam recursos públicos para o manejo de resíduos são Estrela no valor de R $\$ 150.000,00$ por mês e em segundo lugar o município de Taquari com $\mathrm{R} \$ 102.130,00$ por mês. O município de Estrela gasta o equivalente a $R \$ 4,89$ por habitante por mês e Taquari $R \$ 4,60$ por habitante por mês. O que se percebe é não há grandes diferenças nos gastos. Salienta-se que o município de Lajeado afirmou não possuir a informação do quanto é gasto com a gestão de resíduos, no entanto no site da Prefeitura, encontra-se disponível para consulta o Plano Municipal de Gerenciamento Integrada de Resíduos, caracterizando assim, o despreparo e desconhecimentos dos ocupantes dos cargos de chefia e assessoramento de setores táo importantes quanto é o ambiental. Ambos os municípios citados, terceirizam desde a coleta 
até a disposição final de seus resíduos sendo que ambos os respondentes declararam não conhecer a proposta dos consórcios.

Os gastos dos municípios com a coleta e destinação final varia de $\mathrm{R} \$ 7,16$ a $\mathrm{R}$ \$ 2,09 por habitante por mês. O município de Anta Gorda adotou o sistema de coleta, triagem e destinaçáo final através de empresa terceirizada dispensando mensalmente o valor de $\mathrm{R} \$$ 2,09 por habitante/mês, enquanto que o município de Westfália gasta mensalmente $\mathrm{R} \$ 7,16$ por habitante utilizando o mesmo sistema. A terceirização tem sido a opçáo da maioria dos municípios da região, gerando uma disparidade nos gastos desprendido dos cofres públicos.

Se somarmos os valores gastos pelos municípios que retornaram os questionários, verifica-se um montante mensal de $\mathrm{R} \$ 912.667,00$ sendo gasto mensalmente na regiáo, em sua grande parte sendo destinado a empresas terceirizadas, ressalta-se que o município de Lajeado respondeu que não informaçóes acerca dos gastos mensais com a coleta e disposiçáo final dos resíduos. Caso dispostos esses dados, os valores mudariam de forma considerável por ser o município com maior número populacional da região.

Buscou-se identificar se ainda existiam lixões na região e quantos municípios destinam seus rejeitos a aterros controlados, levando em consideração que estes deveriam ser substituídos por aterros sanitários, destinação final ambientalmente correta (Gráfico 01).

Gráfico 01- Forma de disposição final dos resíduos

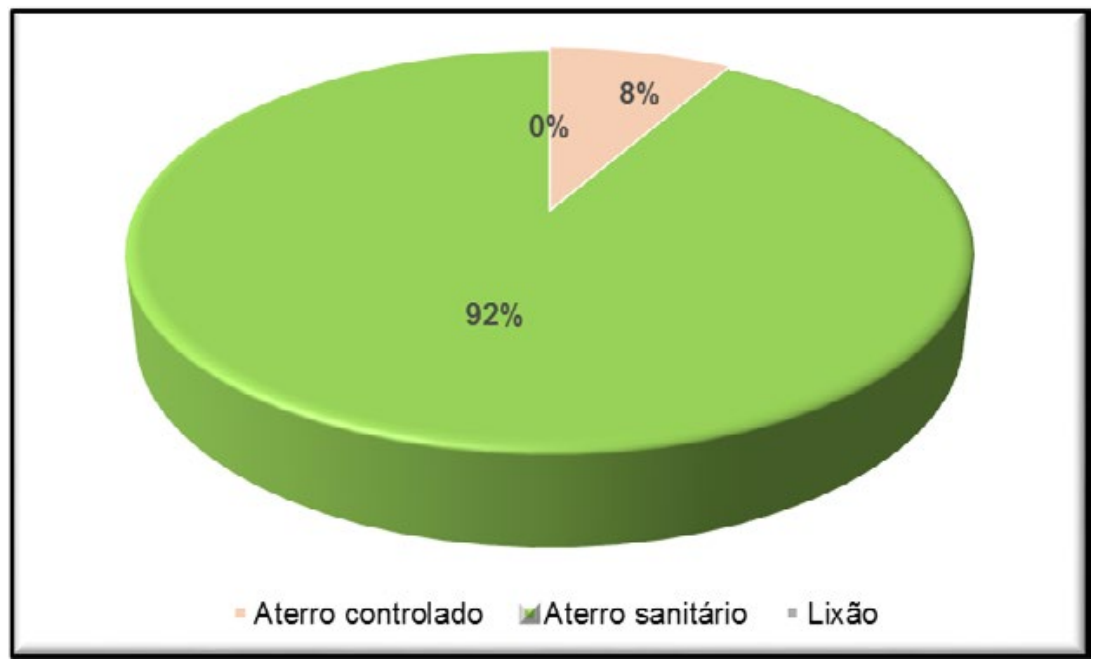

Fonte: Coleta de dados do autor, 2015.

Os dados apresentados no gráfico 01 apontam que os lixões foram extintos na região, atendendo à meta da PNRS, no prazo de agosto de 2014. Também foi possível perceber que mesmo que o aterro sanitário seja uma medida adotada pela maioria dos municípios (terceirizado ou municipal) ainda há aterros controlados na regiáo, atingindo o percentual de $8 \%$ que corresponde a 3 municípios (Anta Gorda, Roca Sales e Ilópolis). 
Gráfico 02 - Forma da prestação dos serviços de coleta e disposição final dos RSU

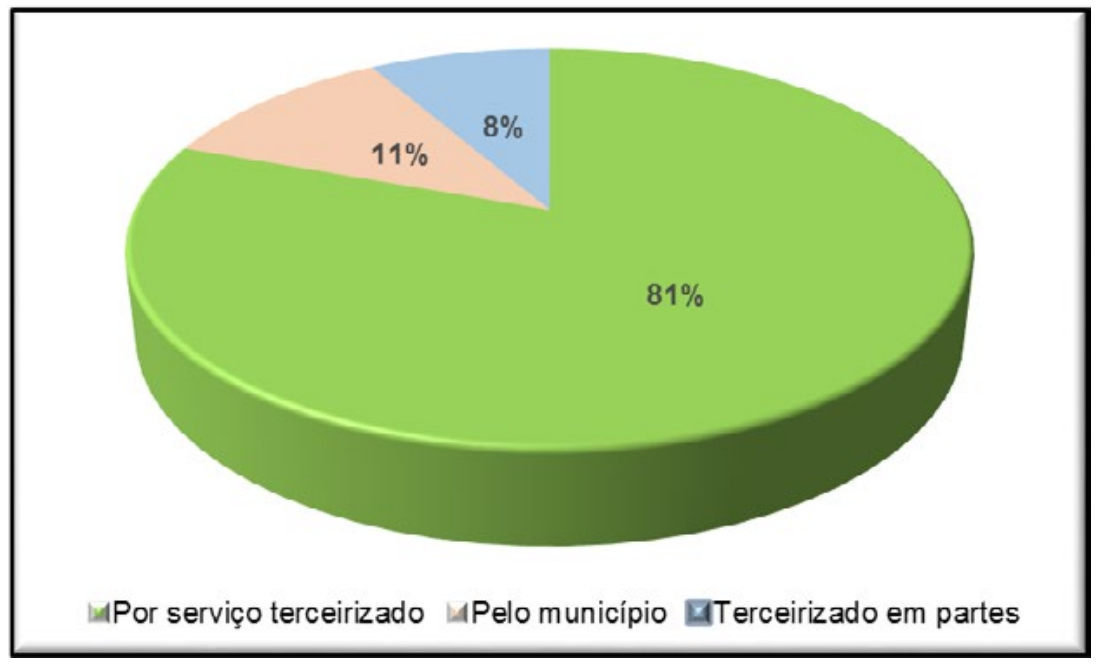

Fonte: Coleta de dados do autor, 2015.

Apenas $11 \%$ ou 4 municípios executam diretamente os serviços de coleta e destinação de resíduos. $81 \%$ terceiriza estas obrigaçóes, enquanto $8 \%$ executa diretamente a coleta e terceiriza a triagem e destinação final (Gráfico 02).

Como a grande maioria terceiriza o manejo de resíduos, buscou-se verificar para onde estấo sendo encaminhados.

Gráfico 03 - Destino final dos resíduos coletados

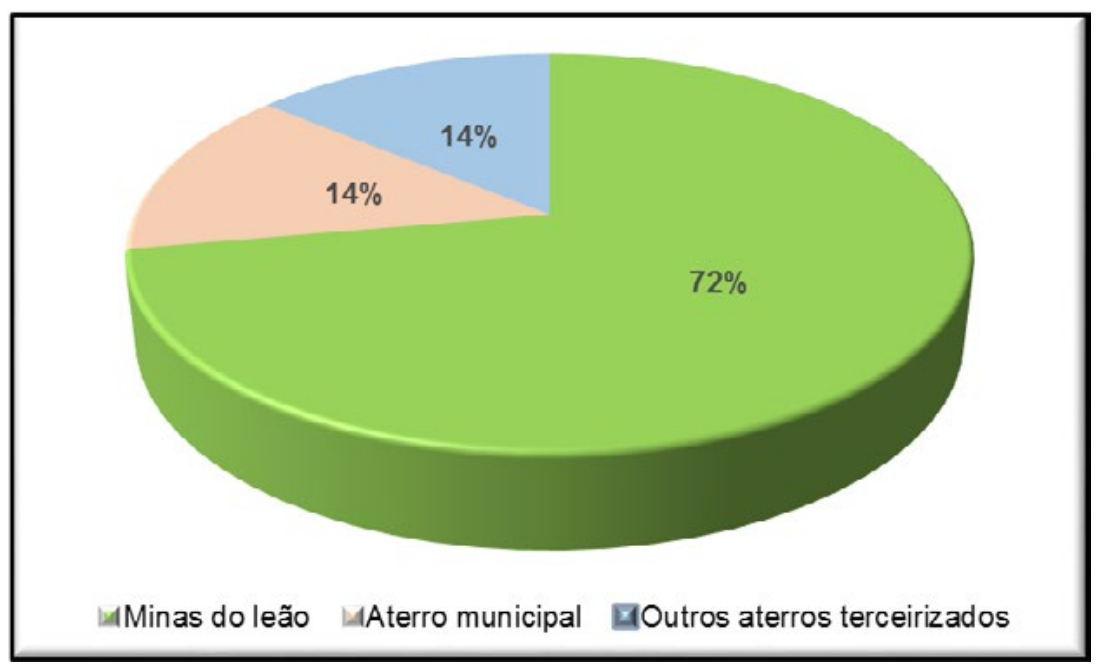

Fonte: Coleta de dados do autor, 2015. 
Com os dados do gráfico 03, averiguou-se que o aterro sanitário de Minas do Leão absorve os resíduos de $72 \%$ dos municípios da região. Como estes municípios realizam a coleta, em média, 3 vezes por semana, resulta em três viagens semanais ao aterro. Isso reflete em dispensação de recursos públicos para pagamento do trajeto que poderia ser economizado se os municípios se unissem para implantar um aterro sanitário em consórcio ou até mesmo de forma paliativa, um sistema de transbordo.

Somente $14 \%$ ou 5 municípios possuem aterro municipal: Estrela, Lajeado, Putinga, Teutônia e Relvado, sendo que apenas Teutônia náo destina à aterro sanitário. O percentual de $14 \%$ dos municípios envia seus rejeitos para outros aterros da regiáo, Ilópolis e Arvorezinha enviam à Canaã com sede em Anta Gorda; Dois Lajeados à empresa Planeta com sede em Serafina Corrêa; Canudos do Vale ao aterro de Candiota e Imigrante ao aterro de São Leopoldo.

Um dos pontos principais da Política Nacional de Resíduos Sólidos é a redução, ou seja, a não geração de resíduos através do tratamento e da reutilização dos mesmos. Já no que diz respeito aos rejeitos, a lei determina uma destinação adequada a eles, sem agredir o meio ambiente. Portanto, todos os municípios deveriam realizar triagem e reciclagem dos resíduos visando o reaproveitamento dos recicláveis e a redução do volume final.

Gráfica 04- O município que realizam triagem/ reciclagem dos resíduos

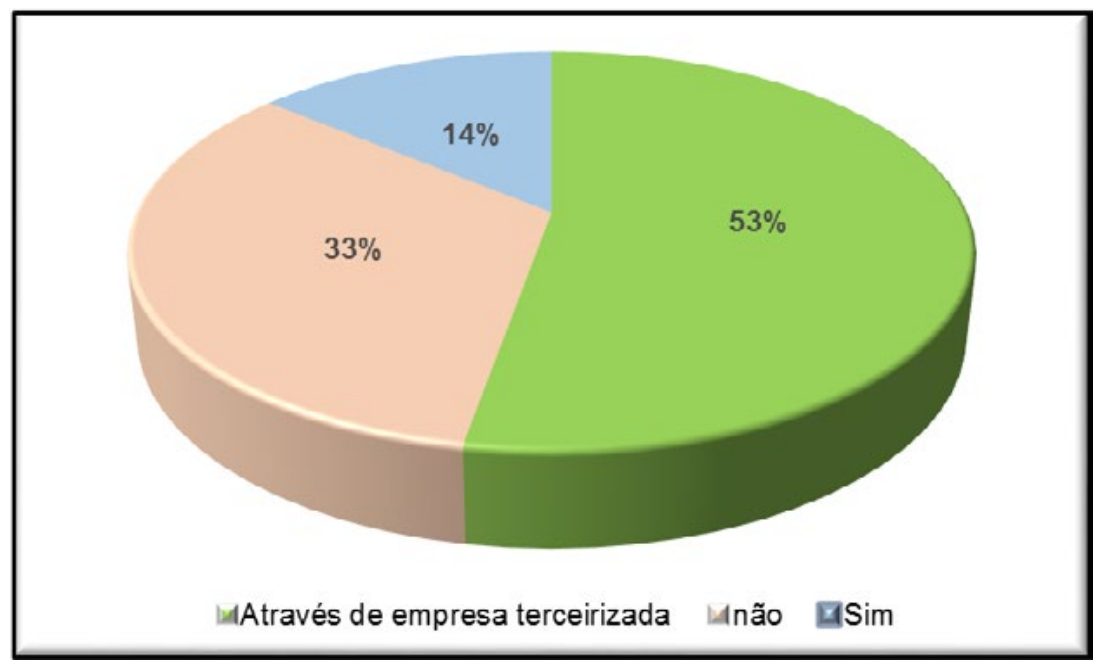

Fonte: Coleta de dados do autor, 2015.

Segundo dados apresentados no gráfico $04,33 \%$ deles não realizam triagem e/ou reciclagem dos resíduos. Considera-se um número expressivo, levando em consideração a importância de tal atividade para o meio ambiente e para o cumprimento das metas estabelecidas na PNRS. Dos 36 municípios do Vale do Taquari 14\% realizam a triagem e reciclagem no próprio município e $53 \%$ fazem através de empresa terceirizada. Os que optaram por terceirizar, na sua grande maioria, enviam seus resíduos direto para as unidades de triagem na sede da empresa contratada. 
Os municípios que enviam seus resíduos para as unidades de triagem optaram pelas empresas Ecotrat com sede no município de Triunfo; Planeta com sede no município de Serafina Corrêa; Empresa Canaã com sede em Anta Gorda e Empresa Adriano Cardoso Silva - ME de Roca Sales, RS Reciclagem com sede na empresa de Barros Cassal; Empresa Biasotto, Ecopal Reciclagem e Transportes com sede no município de Paverama.

Portanto, tem-se o percentual de $67 \%$ de municípios que realizam triagem e reciclagem de resíduos e apenas 33\% deles não realizam, isso significa que todo resíduos gerados nesses municípios são encaminhados direto ao aterro, não havendo aproveitamento dos materiais recicláveis, aumentando o volume final e diminuindo a vida útil do aterro.

A PNRS estabelece a educação ambiental como um de seus instrumentos, reforçando a importância deste conteúdo na elaboração dos planejamentos relacionados aos resíduos sólidos. Portanto, para que os municípios consigam alcançar as metas propostas pela PNRS é imprescindível que tenham iniciativas de educação ambiental para a triagem dos resíduos desde os domicílios.

Verificou-se que $89 \%$ dos municípios do Vale do Taquari possuem iniciativa de educação ambiental. Enquanto $11 \%$ declararam não possuir nenhuma iniciativa. Dos municípios que possuem iniciativa de educação ambiental 6 declaram que esse trabalho se restringe às disciplinas trabalhadas nas escolas. Outros referiam a distribuição de folders. Estes também informaram utilizar mecanismos de educação ambiental não formal que incentivam o descarte consciente, o cadastramento de catadores, a coleta seletiva nas áreas rural e urbana, a criação de postas de coleta de resíduos especiais (pilhas, remédios, etc.), palestras para diferentes grupos sociais entre outros.

A criação e implantação do Plano Municipal de Resíduos Sólidos deve-se às determinaçóes legais previstas nas Leis Federais no 12.305/2010 e 11.345/2007, às quais estão sujeitas as pessoas físicas ou jurídicas, de direito público ou privado, responsáveis, direta ou indiretamente, pela geração de resíduos sólidos e as que desenvolvam ações relacionadas à gestão integrada ou ao gerenciamento de resíduos sólidos, como é o caso dos municípios.

Contudo, apesar da determinação legal e dos esforços em tornar efetiva a PNRS, é evidente a resistência de municípios no cumprimento de tal obrigação legal, tendo em vista que o prazo originalmente proposto de 4 anos definido na legislação federal até 02 de agosto de 2014, para a disposição ambientalmente adequada dos rejeitos não foi cumprida, e poucos municípios apresentaram seus Planos. De acordo com o IBGE (2013) apenas um terço dos municípios brasileiros (33,5\%, ou 1.865 municípios) declararam possuir Plano de Gestão Integrada de Resíduos Sólidos, nos termos estabelecidos na Política Nacional de Resíduos Sólidos até o término do prazo.

O Art. 18, da PNRS preceitua que a elaboração do PMGIRS é pré-requisito para os municípios terem acesso aos recursos do governo federal, a incentivos ou a financiamentos de entidades federais de crédito ou fomento na área de limpeza urbana e resíduos sólidos. Mesmo tendo encerrado o novo prazo para elaboração dos PMGIRS em 02 de agosto de 2015, ainda existem 28\% dos municípios do Vale do Taquari que não haviam apresentando, não podendo acessar recursos financeiros voltados ao manejo de resíduos. 
O município de Arvorezinha informou que o PMGIRS está em fase de elaboração. O município de Sério somente possui o plano intermunicipal de gestão integrada de resíduos confeccionado pelo consórcio G8, abrangendo os municípios consorciados.

Observa-se que os municípios consorciados ao G8 conseguiram atingir as metas da PNRS, pois receberam auxílio técnico, através do consórcio, para elaboração do PMGIRS, implantaçáo da coleta seletiva e projetos de educaçáo ambiental, entre outras metas na referida Lei.

Importante salientar que conforme informação do Ministério do Meio Ambiente os municípios que optarem por soluçôes consorciadas intermunicipais para a gestáo dos resíduos sólidos, possuem a vantagem de ser dispensada a elaboração de plano municipal de gestão integrada de resíduos sólidos (RIBEIRO, 2015).

Outro aspecto analisado, foi o grau de familiaridade dos servidores, respondentes com a PNRS. De acordo com os dados $11 \%$ dos servidores responsáveis pela gestáo de resíduos declararam não conhecer a PNRS, isso representa quatro municípios sendo eles: Lajeado, Vespasiano Corrêa, Fazenda Vilanova, Colinas. Por outro lado, alguns municípios que afirmaram conhecer a PNRS declararam conhecer vagamente como é o caso de Progresso e Paverama.

Salienta-se que para responder a esses questionários foram selecionados servidores preferencialmente efetivos que atuam nos setores responsáveis pela gestão dos resíduos por se acreditar que estes teriam maior conhecimento a respeito da legislaçáo vigente e da atuação do município.

Parece evidente que o mínimo que se exige para ocupar cargos relacionados ao manejo de resíduos é que os servidores tenham domínio acerca do assunto e da legislaçáo relacionada, atualizando-se conforme ocorrerem alteraçóes legislativas.

Os respondentes que alegaram não conhecer a PNRS ou conhecer vagamente ocupam os seguintes cargos: Lajeado (Coordenadora de Limpeza Pública), Vespasiano Corrêa (prefeito), Fazenda Vilanova (Bióloga), Colinas (Coordenador do Departamento do MA). Progresso (Secretário da Agricultura e Gestão Ambiental) e Paverama (Engenheira Agrônoma).

Oito municípios não responderam ou declaram não ter base para responder ao questionamento representando um percentual de $22 \%$ dos municípios. Mas $78 \%$ que indicam conhecer a PNRS. A maioria elencou a logística reversa, a coleta seletiva e a extinção dos lixóes. Outros elencaram os princípios e objetivos da PNRS, demostrando ter informação a respeito.

Chama a atençáo que dos respondentes, 5 afirmaram que nada mudou no município em relação à gestão dos resíduos sólidos domésticos com a aprovação da PNRS em 2010. Nesse sentido, destaca-se a resposta do município de Muçum ao afirmar que "Nada pois para esse contexto é necessário investimento, e não existe entendimento que é necessário por parte da Administração". A afirmação comprava que os investimentos voltados ao manejo de resíduos são negligenciados. 
Dos respondentes 7 afirmaram que houve pouca melhora pois, já haviam realizado coleta seletiva e outras ações em andamento antes da aprovação da PNRS, assim, foram apenas intensificadas, como é o caso do município de Relvado que o respondente afirma:

O município já vinha realizando coleta seletiva mas com a lei houve uma maior conscientização das pessoas quanto ao destino adequado para cada tipo de resíduo. Projetos de educação ambiental se intensificaram e a populaçâo passou a responder melhor perante as campanhas realizadas.

Outro respondente afirma que: "O lixo passou a ser coletado e tratado por empresa terceirizada”. Dos 36 municípios, 19 municípios afirmaram que a aprovação da PNRS trouxe melhorias ao município. A maioria citou a implantação da coleta seletiva, a extinção dos lixóes existentes no município e a elaboração do PMGIRS. Alguns dos municípios que estão consorciados elencaram outras vantagens como é o caso do Município de Canudos do Vale: "Estão sendo realizados projetos junto ao G8 e aguarda-se recursos da FUNASA para que o G8 coloque todas as ações propostas".

De modo geral, constatou-se que ainda ocorre a falta de informação dos respondentes a respeito dos conceitos que envolvem o consorciamento.

Gráfico 05 - Conhecimento dos servidores a respeito dos consórcios Públicos

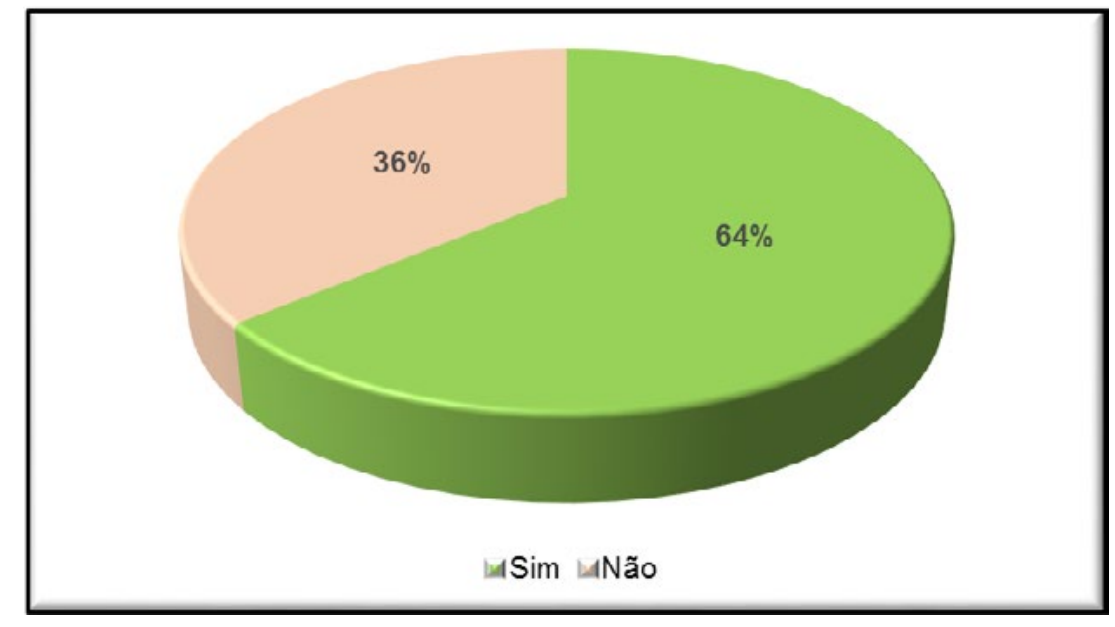

Fonte: Coleta de dados do autor, 2015.

De acordo com os dados apresentados no gráfico 05, 64\% dos respondentes afirmam conhecer a proposta dos consórcios, enquanto que 36\% afirmam não saber do que se trata, correspondendo a 13 dos 23 respondentes que afirmaram conhecer a proposta. 
Gráfico 06 - Opinião sobre a possibilidade do município se consorciar

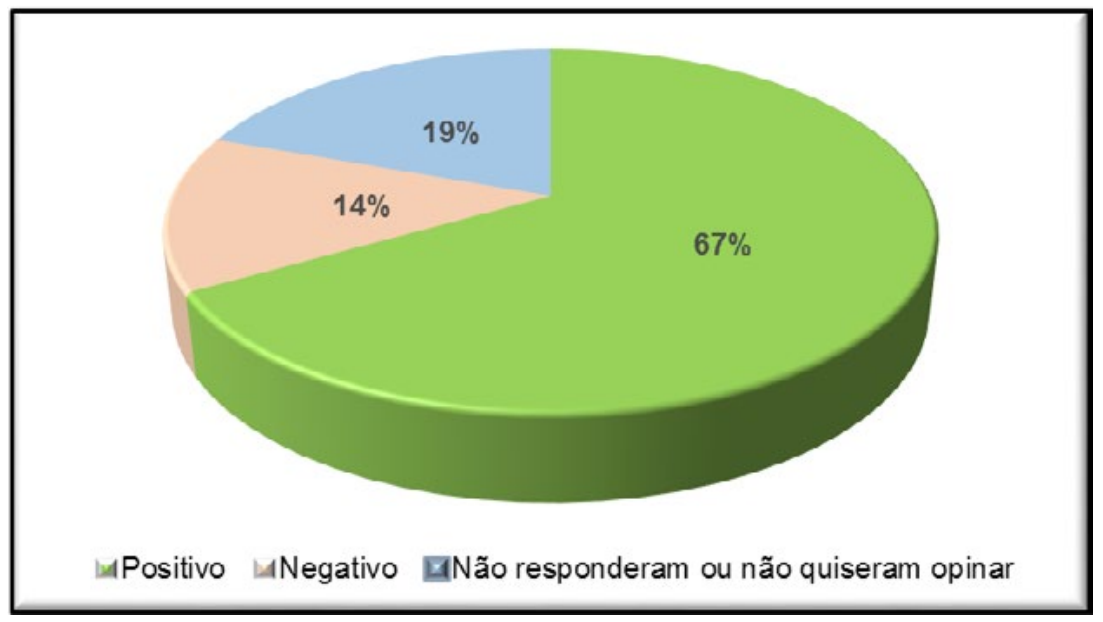

Fonte: Coleta de dados do autor, 2015.

Quanto à possibilidade dos consórcios entre os municípios, as opinióes dos respondentes se dividiram em: $67 \%$ que entendem ser possível a formação de um consórcio e que estes podem apresentar resultados positivos e 14\% (4 municípios) manifestaram a opiniáo negativa ao consorciamento por náo haver interesse por parte do município, também 19\% não responderam ou não quiseram opinar.

Acrescenta-se aos dados apresentados no gráfico 06, que os municípios que se manifestaram em desfavor ao consorciamento elencaram como argumentos: "Não temos interesse", "Nenhuma possibilidade por problemas POLÍTICOS; falta conhecimento por parte dos chefes do executivo"; "Não sou favorável, pois vejo distancia para o transbordo que é um fator negativo"; "Vejo dificuldades na administração e entraves burocráticos e legais". Percebe-se que entre os argumentos, apesar de se evidenciarem resistências à formaçáo de novos consórcios, demostram como fatores limitantes, as questóes políticas partidárias e a falta de conhecimento por parte dos gestores e servidores públicos.

Quanto àqueles municípios que manifestaram-se positivamente, argumentos evidenciam a existência de problemas comuns e a necessidade de soluçóes coletivas: "É uma oportunidade de fortalecer os entes públicos, os quais unidos têm mais expressividade nas suas reivindicaçôes junto aos órgãos que representam outras esferas de Governo"; "hoje trabalhamos com consórcio de saúde por exemplo e a ideia deu certo, então acredito que essa ideia seria viável."; "Seria bom, pois vejo o consorcio como forma de "união de forças", uma vez que, os municípios tem carência de verbas e recursos, que é o que na maioria das vezes os impede de levar um projeto ao fim"; "Acredito ser válida esta possibilidade, pois os problemas de cada município se assemelham e juntos se torna mais fácil de resolvê-los"; "É uma ótima opção, principalmente para municípios menores, pois desta forma conseguem se organizar para alcançar um objetivo em comum, além do acesso a recursos financeiros e possibilidades de outros trabalhos integrados com os municípios integrados"; "Acho que as administrações municipais do Vale do Taquari deveriam pensar cada vez mais em consórcios 
para todas as áreas, pois, os nossos municípios são na grande maioria pequenos, juntos eles teriam mais força e menos gastos. Falando de Fazenda Vilanova a possibilidade do município se consorciar depende da administração municipal. Mas o que depender do meu setor terá todo o apoio"; "toda a parceria que vise favorecer o município para a conquista de elementos que possibilitem uma melhora na qualidade dos serviços prestados merece no mínimo o estudo da viabilidade da mesma". "Os municípios trabalhando juntos podem se tornar uma forma de ser mais viável para cada um”. Percebe-se que os servidores que participam ou conhecem experiências de consórcios elencam vários fatores favoráveis positivos.

Chama a atençáo a contrariedade nas respostas apontadas pelo respondente de um dos municípios que quando questionado se conhece a proposta de consórcio (questão 18) respondeu que conhece. Já na questão 19, quando buscou-se verificar conhece alguma experiência, afirma que não e, na questão 20, responde: "Acredito que seja um futuro próximo". Porém, o município está consorciado desde 2011, sendo que o prefeito o presidente do Conselho de Prefeitos do Consórcio G10.

A maioria respondeu, que se consorciaria com municípios mais próximos ou limítrofes. Oito municípios afirmaram que estão consorciados e que se fossem firmar novos convênios seria com os municípios do G8, enquanto alguns afirmaram se seria com os municípios da AMVAT. Assim, evidencia-se que a proximidade é determinante, ressalta-se que 12 municípios não responderam a essa questão.

\section{CONSIDERAÇÓES FINAIS}

A Política Nacional de Resíduos Sólidos constituiu objetivos e metas claras sobre o tema. Entre elas podemos citar: a eliminação e recuperação de lixões, associadas à inclusão social e à emancipação econômica de catadores de materiais reutilizáveis e recicláveis seguindo a ordem de prioridade de não geração, redução, reutilização, reciclagem, tratamento e disposição final ambientalmente adequada dos rejeitos. Entre as principais exigências pode-se citar a implantação da coleta seletiva e a elaboração do Plano Municipal de Gestão de Resíduos.

Essas metas, para as municipalidades, tornaram-se um grande desafio. Há municípios que carecem de recursos para investir na área de saneamento básico ou não priorizam estas áreas como é o caso dos de pequeno porte. Nesse sentido, a Lei dos Consórcios Públicos veio atender à lógica da formação de um Estado Federado, que é a da cooperação entre seus entes, a qual é relevante para a realização dos serviços públicos básicos à população. $\mathrm{A}$ cooperação pode resultar em melhor qualidade de vida, eficiência nos serviços prestados e economia nos recursos financeiros.

Nesse sentido, buscou-se verificar se seria viável a implantação do consórcio público intermunicipal de gerenciamento de resíduos sólidos domésticos na região do Vale do Taquari, RS, tendo-se como base a legislação relativa ao trato dos resíduos e pertinente aos consórcios públicos. Os estudos evidenciam que a região ainda precisa avançar para cumprir as metas da PNRS. Referente à coleta seletiva foi possível constatar que apenas $56 \%$ dos municípios conseguiram implantar a coleta seletiva. Ainda restam $44 \%$ dos municípios que náo conseguiram cumprir essa exigência legal, no momento da coleta de dados. A partir da 
referida lei, a coleta seletiva passou a ser obrigatória, pois sem a coleta seletiva, ficará restrito o acesso aos recursos do governo federal e, de acordo com o preceito contido no artigo $18 \mathrm{da}$ Lei 12.305/2010, o governo prioriza o acesso a recursos federais aos municípios que atuam em consórcios e os que implantaram a coleta seletiva.

Um aspecto importante é que a região conseguiu atender a meta de extinguir os lixóes até o ano de 2014. Porém, apesar da rigidez legal e o fato da FEPAM náo estar licenciando aterro controlado desde 2012, a regiâo ainda possui $8 \%$ dos municípios destinando seus resíduos dessa forma. Não existem lixóes na regiáo.

Quanto ao serviço de coleta e destinação final, $81 \%$ dos municípios terceirizam, sendo que o aterro sanitário privado de Minas do Leáo absorve os resíduos de $72 \%$ dos municípios da regiáo. Como os custos da terceirização são altos, o consorciamento com gestão responsável, pode ser vantajoso. Quanto à meta de implantar programas de educação ambiental, $89 \%$ dos municípios do Vale do Taquari possuem iniciativa de educaçáo ambiental. Sabe-se que a educação ambiental é de suma importância no processo de redução nos índices de geração de resíduos e segregação. Enquanto que $11 \%$ declararam não possuir nenhuma iniciativa.

Entende-se que um projeto de educação ambiental integrado à gestão dos resíduos é fundamental. Isto porque a educação ambiental pode reorientar a educação para o desenvolvimento sustentável de forma a compatibilizar os objetivos sociais (de acesso a necessidades básicas), os objetivos ambientais (de preservação da vitalidade e diversidade do planeta). Isso concede direito aos cidadáos a um ambiente ecologicamente saudável e os objetivos econômicos; além de aumentar a conscientização popular (PHILIPPI, 2004, p.477).

Um aspecto negativo a se destacar é que mesmo tendo encerrado prazo para elaboração dos PMGIRS em 02 de agosto de 2015, cerca de um terço dos municípios não o haviam apresentado, náo possuindo acesso a recursos financeiros voltados ao manejo de resíduos conforme art. 18 da PNRS.

Os respondentes, apesar de responsáveis pelo tema nas administraçóes, evidenciam pouco esclarecimento sobre os objetivos e metas da PNRS, isto mesmo tendo selecionado servidores preferencialmente efetivos, que atuam nos setores responsáveis pelo manejo de resíduos, ocupando cargos como: Coordenação de limpeza pública, prefeito, Biólogo, Coordenador do Departamento de Meio Ambiente, Secretários da Agricultura e Gestão Ambiental e Engenheiro Agrônomo, entre outros.

Assim, observa-se que os municípios carecem de qualificação profissional na prestação dos serviços públicos, devendo necessariamente, nesses setores importantes de execução de programas e políticas públicas contínuas, centralizar informaçōes em servidores efetivos, para que nas trocas de mandatos políticos náo se percam informaçóes importantes e se consiga dar continuidade às políticas públicas previstas na Constituição Federal.

Quanto ao grau de informação dos servidores acerca dos consórcios públicos, 64\% dos respondentes afirmam conhecer a proposta dos consórcios, ao menos saber em que consiste, porém, desses, poucos tiveram a oportunidade de ter contato com uma experiência concreta. 
Mesmo assim, 67\% entendem ser possível a formação de um consórcio e que estes podem apresentar resultados positivos principalmente nos municípios próximos. Apenas $14 \%$ manifestaram-se contrários.

Portanto, quanto à implantação de consórcios para o gerenciamento de resíduos sólidos urbanos nos municípios que compóem o COREDE - Vale do Taquari, conclui-se que é necessária diante dos dados coletados, que informam que $44 \%$ dos municípios não conseguiram cumprir a exigência legal de implantação da coleta seletiva, o que restringe $o$ acesso aos recursos do governo federal; $8 \%$ dos municípios ainda destinavam os resíduos para aterro controlado; $81 \%$ dos municípios terceirizavam a coleta e destinaçáo de $72 \%$ dos resíduos produzidos na regiáo para o aterro sanitário privado, de Minas do Leáo, o que envolve altos custos e a exigência de transporte de muitos caminhóes por cerca de 200 quilômetros; um terço dos municípios não havia apresentado o PMGIRS e assim, estavam sem acesso aos recursos financeiros voltados ao manejo de resíduos, conforme previsto no art. 18 da PNRS; e havia pouco esclarecimento sobre os objetivos e metas da PNRS dos servidores que responderam aos questionários, em relação ao manejo de resíduos. Ainda, evidenciou-se a presença de consórcio ativo na região, o G8, que inclui $22 \%$ dos municípios o que corresponde a 8 dos 36 que compóem o COREDE. Também, levantou-se que $67 \%$ entendem ser possível a formação de um consórcio e acreditam que este tenha resultados positivos para os municípios. Os dados construídos por meio da pesquisa evidenciam que há necessidade de uma solução coletiva para a gestão dos resíduos na regiáo, na qual muitos municípios não adequaram-se à legislação, e eles têm a seu favor a vantagem de proximidade, portanto há potencialidade de consorciamento, o que depende de questóes subjetivas e partidárias relacionadas aos gestores públicos.

No entanto, há que se atentar para o fato de que faltam esclarecimentos a respeito da Lei dos Consórcios e a proposta do consorciamento, pois as noções são vagas, sem consistência e apenas uma minoria obteve contato direto com algum consórcio existente. É necessário dar publicidade à Lei dos Consórcios e sua aplicabilidade, bem como às experiências positivas já concretizadas no Estado do Rio Grande do Sul, a fim de fomentar a criação de novos acordos de cooperaçáo intermunicipais para que os municípios consigam, atingir as metas e objetivos da PNRS, reduzindo gastos com a prestação dos serviços básicos, minimizando os impactos no meio ambiente e atendendo ao preceito constitucional da eficiência, previsto no artigo 37 da Constituiçáo Federal, de caráter obrigatório ao administrador público. Deve-se também articular-se com as organizaçōes existentes como o Conselho de Desenvolvimento do Vale do Taquari (CODEVAT), a Associação dos Municípios do Vale do Taquari (AMVAT) para realizar estudos de viabilidade para tal implantação.

\section{REFERÊNCIAS}

ABRELPE. Panorama dos Resíduos Sólidos no Brasil: 2011. Disponível em: <http:// www.abrelpe.org.br/Panorama/panorama2011.pdf>. Acesso em: 14 de abril de 2012.

Panorama dos Resíduos Sólidos no Brasil: 2016. Disponível em: <http://

www.abrelpe.org.br/Panorama/panorama2016.pdf>. Acesso em: 04 de setembro de 2017. 
BATISTA, Sinoel et al. Guia de consórcios públicos: As possibilidades de implementação do consórcio público. Brasília: Caixa Econômica Federal, 2011c. v.3.

BESEN, Gina Rizpah. Coleta seletiva com inclusão de catadores: construção participativa de indicadores e índices de sustentabilidade. 2011. 275 f. Tese (Doutorado) Faculdade de Saúde Pública, Universidade de São Paulo, São Paulo, 2011.

BRASIL, Constituição (1988). Constituição da República Federativa do Brasil. Brasília, Disponível em: <http://www.planalto.gov.br/ccivil_03/constituicao/constitui\%C3\%A7ao .htm>. Acesso em: 20 abr. 2016.

, Lei n. 11.107, de 06 de abril de 2005. Dispóe sobre normas gerais de contrataçáo de consórcios públicos e dá outras providências. Disponível em: $<\mathrm{http}: / /$ www.planalto.gov.br/ccivil_03/_ato2004-2006/2005/Lei/L11107.htm>. Acesso em: 26 abr. 2016.

, Lei n. 12.305, de 02 de agosto de 2010. Institui a Política Nacional de Resíduos Sólidos; altera a Lei $\mathrm{n}^{\circ}$ 9.605, de 12 de fevereiro de 1998; e dá outras providências. .Disponível em: http://www.planalto.gov.br/ccivil_03/_ato20072010/2010/lei/l1 2305.htm. Acesso em: 15 abr. 2016.

CALDERAN, Thanabi Bellenzier. Consórcios públicos Intermunicipal de

Gerenciamento de Resíduos Sólidos Domésticos: Estudo de caso. Dissertação. Centro Universitário Univates. Programa de Mestrado em Ambiente e Desenvolvimento, 2013.

FIORILLO, Celso Antônio Pacheco. Curso de direito ambiental brasileiro. 6. ed. São Paulo: Saraiva, 2005.

GOMES, Daiene da Silva. Resíduos Sólidos Urbanos Gerados no Rio Grande do Sul. Revista Pollution Engineering. v.7, n. 02, p. 25-30, jul. 2010.

JACOBI, Pedro Roberto; BESEN, Gina Rizpah. Gestão de resíduos sólidos em São Paulo: desafios da sustentabilidade. Estudos Avançados da Universidade de Sáo Paulo, São Paulo, v. 25, n. 71, p. 135-158, abr. 2011.

INSTITUTO BRASILEIRO DE GEOGRAFIA E ESTATÍSTICA (IBGE). Censo demográfico 2010. Disponível em:<http://www.ibge.gov.br/home/estatistica/populacao/ censo2010/default_resultados_amostra.shtm>. Acesso em: 05 de abril de 2014.

LIMA, José Dantas de. Consórcio de desenvolvimento intermunicipal: instrumento de integração regional. Rio de Janeiro: ABES, 2003.

MORAES, José Laécio. Os consórcios públicos e a gestão integrada de resíduos sólidos em pequenos municípios do estado do Ceará, Brasil. Revista Geonorte, Amazonas, ano 3, n.4, p. 1171-1180, jun. 2012. 
PEIXOTO, João Batista. Manual de implantação de consórcios públicos de saneamento. Brasília, 2008.

PHILIPPI. Arlindo jr; ROMERO. Marcelo de Andrade; Bruna. Gilda Collet. Curso de Gestáo Ambiental. Ed.Manoele. São Paulo, 2004.

RIO GRANDE DO SUL. Plano Estadual de Resíduos Sólidos Rio Grande do Sul PERS - RS. Porto Alegre, 15 de outubro de 2014. Disponível em: http://www.pers.rs.gov. br /arquivos/PERS-SEMA-Audiencia\%20Panorama\%20RS\%20-\%2015-10-2014\%20 -\%20REV03.pdf>. Acesso em: 14 de abril de 2015.

. Plano Estadual de Resíduos Sólidos Rio Grande do Sul PERS - RS. Porto

Alegre, 15 de outubro de 2014. Disponível em: http://www.pers.rs.gov.br/arquivos/PERSSEMA-Audiencia\%20Panorama\%20RS\% 20-\%2015-10-2014\%20-\%20REV03.pdf. Acesso em: 14 de abril de 2016.

SILVA, Norma Laís da Silva e. Aterro sanitário para resíduos sólidos urbanos - RSU - matriz para seleçáo da área de implantação. 2011. 68 f. Trabalho de Conclusão de Curso. Departamento de Tecnologia da Universidade Estadual de Feira de Santana como requisito para obtenção de título de bacharel em Engenharia Civil, Feira de Santana, 2011.

SIMONETTO, Eugênio de Oliveira e BORENSTEIN, Denis. Gestão operacional da coleta seletiva de resíduos sólidos urbanos: abordagem utilizando um sistema de apoio à decisão. Gestáo \& Produçáo, São Paulo, ano 13, n. 3, p. 449-461, set. - dez. 2006.

SOARES, Daniel Miranda. Transferências tributárias e a Lei Robin Hood. Disponível em: <http://www.artigos.com/artigos/sociais/economia/transferencias-tributarias-e-a-leirobin-hood-1934/artigo/>. Acesso em: 20 de maio de 2011. 